\title{
SOME DISTURBANCES OF THE RHYTHM OF THE HEART
}

\author{
BY \\ JOHN COWAN $\dagger$ \\ (From the Royal Infirmary, Glasgow)
}

\section{INTRODUCTORY}

The association of changes in the character of the pulse and serious cardiac symptoms was recognized many centuries ago, and carefully studied with all the means available at the time. But the significance of the arrhythmias has only been elucidated within the last few years, by the use of instrumental methods of analysis. In G. A. Gibson's text-book (1898), designed to be a mirror of the state of medical science and art at the close of the nineteenth century, only a couple of pages are devoted to the disturbances of the cardiac rhythm. James Mackenzie's book (1902) started an intensive study, and in his Morison Lectures, Gibson (1904) discussed paroxysmal tachycardia, extrasystole, and heart block. The study has continued, and our accumulated knowledge is now vastly greater than it was ten years ago, but there are still gaps on the clinical side. The following records are brought forward to augment the available data.

In the healthy individual each beat of the heart is occasioned by stimuli arising in the sino-auricular node, and spreading from it to the auricles and ventricles. The sinus pacemaker is under the control of the nervous system, and both the rhythm and the rate of the heart may be altered by nervous influences. "The heart responds to every emotion and sensation, and even thought, as well as to the demands created by muscular exertion or the organic processes such as digestion. . . . All states of the nervous system are reflected upon the circulation, each emotion being attended with its own reaction upon the heart and arteries, and even sensation producing recognizable results, so it is to be expected that diseases of the nervous system will be attended with special symptoms, manifested through the circulation, and by the pulse" (Broadbent, 1890). Stokes (1854) had previously referred to the influence of the nervous system upon the circulation, but he concluded that such disturbances of the pulse were more often related to functional disturbance rather than to organic disease of the nervous system, in contradistinction to disturb- 
ances due to intrinsic cardiac causes, which were more often organic than functional.

Disturbances of the pulse may also arise from toxic causes, the activity of such poisons as digitalis or those of the infections ; though these doubtless act by their influence upon the nervous system or the heart itself.

In recent years attention has been largely focused upon the disturbances due to intrinsic cardiac causes ; those due to nervous and toxic causes have received little consideration. It is very important to recognize the nervous origin of an irregular pulse, for the mere suggestion of heart disease may cause incalculable mischief. We have all seen such cases. One came recently under my observation. I saw him first at the age of 13 , when he gave a wonderful display of extrasystoles, clearly due to nervous causes. He was a big, healthy, growing schoolboy, who played all games with acceptance. He was advised to carry on ; but other advice was sought, and he was made an invalid. At the age of 27 he is an undersized, poorly developed, badly nourished hypochondriac. His heart still seems quite sound.

The present paper is mainly concerned with those disturbances of the cardiac rhythm which are due to causes outwith the heart.

The rhythm and the rate of the pulse in health are not absolutely regular. The rhythm, though apparently regular to the finger, is always irregular if accurately measured. During inspiration the rate is quickened and during expiration slowed. The rate of the pulse varies : fever may raise it to 120 per minute ; jaundice may lower it to 40 ; and comparable changes may occur from physical, psychical, or organic nervous influences. The variations are due to variations in the duration of diastole, the intrinsic mechanism of the heart continuing unchanged.

In health each beat of the heart is occasioned by stimuli arising in the sinoauricular node. Every part of the heart, however, possesses the inherent power of initiating stimuli, and the sino-auricular node only takes the lead because its rate of stimulus production ( $70-80$ per minute) is more frequent than that elsewhere. The rate of the auriculo-ventricular node is $50-60$; that of the ventricular muscle 20-30.

The heart may, at times, serve two masters. In many people stimuli occasionally arise elsewhere than in the sino-auricular node and cause a contraction: an extrasystole. If it concerns the ventricles alone, the normal sino-auricular rhythm of the auricles need not be disturbed, but an auricular extrasystole disturbs the sino-auricular rhythm for the moment.

If the rate set by the sino-auricular node becomes less than that set by the auriculo-ventricular node, the latter may take charge and cause a ventricular contraction. This may occur if the activity of the sino-auricular node is depressed so that its rate of stimulus production becomes less frequent than that of the auriculo-ventricular node. This can be caused, in experiment, by cooling the sino-auricular node ; by pressure upon the carotid sinus or the eyeballs ; by heavy doses of digitalis or quinidine. Cushny (1925) showed that in digitalis poisoning in animals, the rate of the auricular contractions 
became less frequent and the irritability of the ventricles exaggerated, so that spontaneous contractions of the ventricles ensued, and, becoming more frequent, eventually established an "idio-ventricular rhythm," with a rate that might be equal to or more frequent than that of the auricles. The mechanism was clearly nervous, for if the vagus inhibition was put out of action by atropine the normal rhythm was restored.

The rate of stimulus production of the sino-auricular node may also become less frequent than that of the auriculo-ventricular node if the latter becomes hyper-irritable. This can be accomplished, in experiment, by warming the auriculo-ventricular node; by the exhibition of atropine throwing the vagus nerve out of action; by stimulation of the right vagus and left sympathetic nerves. In some cases more than one mechanism may be simultaneously in action.

As a rule, when the auriculo-ventricular node takes charge, the stimulus passes in a retrograde fashion to the auricles and causes an auricular contraction. In the case of an isolated auriculo-ventricular nodal extrasystole, this may not occur if the nodal stimulus reaches the auricle at a time when its muscle is refractory ; but if the stimuli are repeated the auricular rhythm is generally set by the auriculo-ventricular node (Nodal rhythm). In exceptional cases this retrograde conduction is disturbed, and the auricular contractions arise in response to stimuli originating in the sino-auricular node, while the ventricular contractions are in response to stimuli from the auriculo-ventricular node (Dissociation). But, curiously, in some cases where retrograde conduction is impeded the forward conduction of stimuli is not altogether inhibited, and at rare intervals the ventricles may respond to a sino-auricular stimulus flowing through the auricular muscle (Capture : dissociation with interference).

The majority of these cases are associated with an infrequent sinus rate and occur during the administration of digitalis ; but dissociation may occur apart from such drugging, the result of purely nervous causes.

The most frequent cause of dissociation is, of course, heart-block, due to damage to the auriculo-ventricular bundle, interrupting the passage of the stimuli from auricle to ventricle. The auricles continue to contract at the sinus rate, whatever it may be, while the ventricles contract infrequently, 20-30 times a minute. The pulse rate in heart-block is less frequent than in dissociation, for the ventricular contractions are due to stimuli arising in the muscle of the ventricle, and not, as in dissociation, in the auriculo-ventricular node. The interruption of the pathway between auricles and ventricles in full heart-block prevents the sino-auricular node from regaining control of the ventricular contractions even on occasion.

Heart-block is generally due to organic lesions in the tissues concerned, but may be of functional origin. It has been produced experimentally by digitalis and quinidine intoxication ; by vagal stimulation; by asphyxia ; in anaphylactic reactions. It has been produced clinically by digitalis, and by pressure upon the carotid sinus or the eyeballs. If of functional origin it can 
be removed by atropine; but if due to organic lesions atropine is inactive, and the ventricles pursue their slow rhythm uninfluenced by exertion, atropine, or vagal stimulation. An exception to this statement has been reported by Fleming and Stevenson (1928). A child, aged $3 \frac{1}{2}$ years, with full heart-block and congenital heart disease, showed an increase in the auricular and the ventricular rates on the exhibition of atropine, although the block persisted unchanged.

The rate and the rhythm of the ventricular contractions may thus be affected by variations in the "tone" of the sino-auricular and the auriculo-ventricular nodes ; and this may be due to functional or organic disturbances, depressing or exalting their particular functions. If the rate of the stimulus production in the two nodes is approximately similar, trifling alterations in rate of either may alter the rhythm for the time. Sinus irregularities, sino-auricular block, nodal rhythm, dissociation, extrasystoles may thus all occur, in quick succession or on separate occasions, in the same patient, as will appear in the following clinical records.

Disturbances of the rhythm of the heart may be due to intrinsic disorders of the heart or to causes arising outwith the organ. The prognosis and the treatment of the two groups vary according to the cause of the disturbance.

\section{ARRHYTHMIAS OF THE SINO-AURICULAR NODE}

Sinus Arrhythmia.-Sinus irregularity of the pulse occurs most notably in children and young adults. The rate and the rhythm of the pulse are unstable. The intervals between the beats are variable, and diastole may be considerably prolonged (Fig. 1). The irregularity is often associated with the phases of

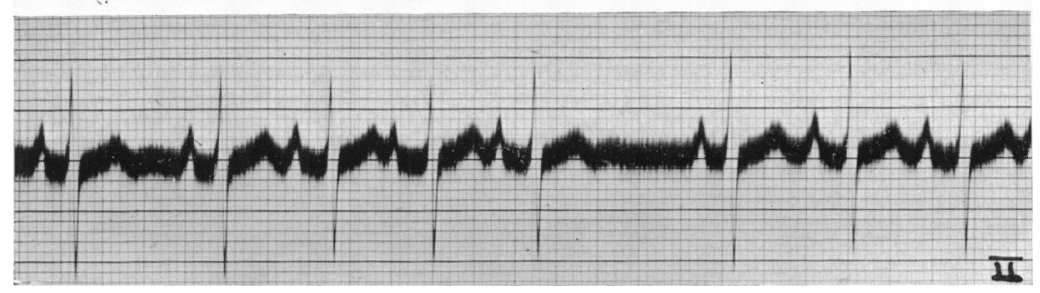

FIG. 1.-Sinus arrhythmia. The only abnormal feature is the varying length of diastole. Lead II.

respiration, the rate quickening with inspiration and slowing with expiration. It is most distinct when the heart is beating slowly, and is lessened or abolished if the rate is increased, as, for instance, by exertion, or the administration of atropine. It can generally be influenced by voluntary changes in the respiratory rhythm, frequent, infrequent, or irregular breathing. The patients show active reflexes and are often highly strung.

It is rarely difficult to recognize sinus arrhythmia. Its relation to the respiratory phases and its disappearance with an increased pulse rate make its nature clear. The electrocardiogram shows variations in the duration of diastole and normal complexes. 
Sinus arrhythmia is a physiological occurrence, and does not require any alteration of the usual habits of the individual, or any treatment.

Sino-Auricular Block: Type A, with Ventricular Standstill.-As already mentioned, the rhythm of the sino-auricular node is not perfectly regular. On occasion a sinus stimulus may default and the pulse misses a beat, neither auricle or ventricle contracting : sino-auricular block. The duration of the diastole is usually double that of the normal rhythm, but it may be somewhat shorter. Sometimes several beats in series may fail, and the standstill may last for several seconds.

Case A. Fig. 2 shows sino-auricular block. An active old man, aged 71, when stooping to pick up some papers, tumbled down unconscious. He recovered in a

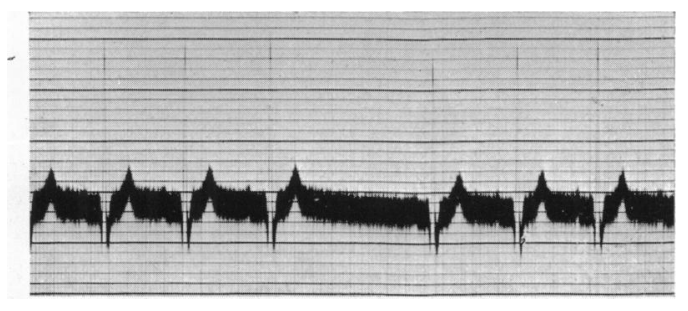

Fig. 2.-Sino-auricular block; type A. Case A. A single contraction of the heart fails. Lead I.

few moments, but his face was bruised and he stayed at home for a day or two before resuming work. A similar attack occurred a year later. Two months afterwards, in August, he was rather short of breath upon exertion, and he had a third syncope when out walking, but was able to return home. His pulse was now found, for the first time, to be infrequent and irregular. In September he looked healthy and active, but his lips were somewhat blue. The left heart was slightly enlarged; the first sound was impure ; the second aortic sound emphatic. His pulse was regular, save for an occasional extrasystole, and infrequent, 30-40 per minute. The electrocardiogram showed dissociation with interference (see Fig. 14, p. 16).

The pulse rate remained unaltered for a fortnight, and then gradually rose, reaching normal figures (60-72) before the end of a month. In December he looked well, but did not feel inclined for much work. His pulse at first was regular, save for an occasional extrasystole, and numbered about 66. But while electrocardiograms were being taken pauses, of which he was unconscious, occurred between the cardiac contractions (Fig. 2). The standstills varied in duration. Sometimes a single beat failed, sometimes several. One standstill lasted for $3 \cdot 3$ seconds.

His subsequent life was short. On January 5 he felt bilious, and stayed in bed. He became drowsy on the 7th, the stupor deepened, and he died in coma on January 10. No paralysis was detected, but the pupils and the reflexes became unequal and the breathing of Cheyne-Stokes type. The pulse rate was unaltered, but the cardiac contractions ceased for a second or two at intervals. Eight pauses were recorded in a tracing during 123.5 seconds, and while $a$. $c$. and $v$. were clear with each beat in the jugulo-carotid curve the line was straight during the pauses.

The striking feature of his illness was the almost complete absence of symptoms of cardiac disability. The breathlessness experienced in August disappeared after two or three weeks and did not recur. There were never any signs of congestive failure. The end came with symptoms of cerebral character, and the sino-auricular block seemed due to a similar cause. 
Case B. The patient was a lonely old bachelor, aged 54, who was seen for some trivial digestive disturbance. His organs seemed sound, but his pulse rate was infrequent, about 47 per minute, and irregular, a sinus irregularity with sino-auricular block (Fig. 3). His discomforts rapidly passed away. Two years later he complained

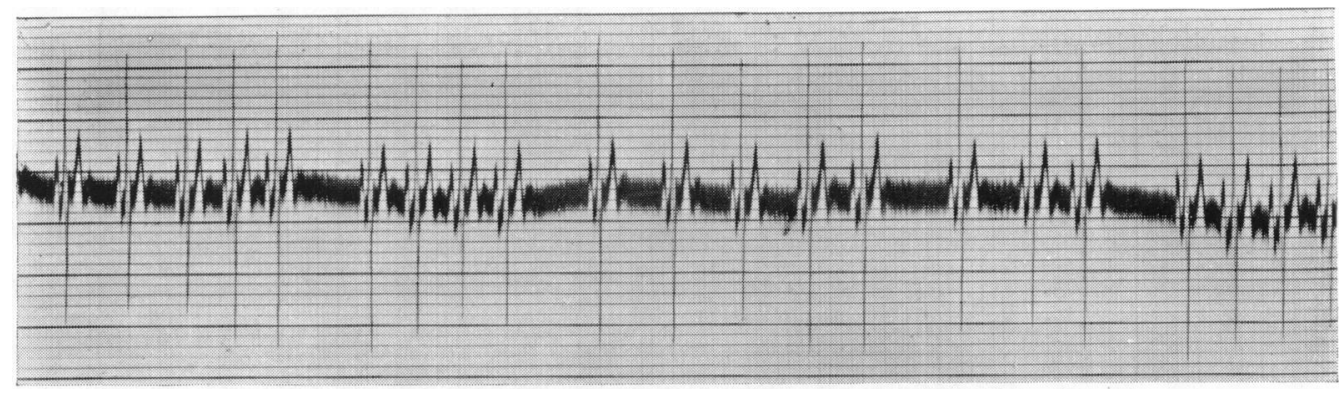

FIG. 3.- Sinus arrhythmia and sino-auricular block : type A. Case B. The record shows a series of progressively shortening auricular diastoles, leading up to long diastolic pauses. The disturbance of the auricular rhythm may be due to extreme sinus arrhythmia or to a sino-auricular block which displays features analogous to Wenckebach periods in auriculo-ventricular block. Lead II.

of his sense of taste ; his electrocardiogram showed an almost regular pulse of 43 per minute and normal complexes. Nine years later he is in good health. There was clearly a neurotic factor in all his complaints.

I can find few clinical records of cardiac standstill from sino-auricular block. Laslett's case (1908) is interesting, for the patient has now been under observation for nearly thirty years. A married woman, she enjoyed good health until the age of 36 (1904), when she became subject to syncopal attacks. In 1908 she was slightly anæmic and rather breathless on exertion. Some hæmic murmurs were audible on auscultation, but her organs otherwise seemed sound. The attacks recurred at intervals of three or four weeks, and were repeated for several days. The pulse, which usually was regular in rhythm and about 70 per minute, on these occasions became infrequent (30-40), as the heart often failed to contract, the result of sino-auricular block. If the standstill lasted for 4-5 seconds she lost consciousness, and if for longer the fingers might twitch. On one occasion she lost her speech for a week. Dr. Laslett courteously informs me (1937) that the attacks still recur as frequently as thirty years ago. She had a stroke two years ago, which has left her slightly aphasic and very decrepit, but she has never shown any signs of cardiac insufficiency. The rhythm of her heart is very sensitive to pressure upon the carotid sinus, and long pauses between the contractions are readily produced in this way.

Heard and Strauss (1918) reported the case of a woman, aged 36, with tonsillitis and a dry pleurisy. She had been liable to "faints" since the age of 16. These attacks commenced with discomfort in the precordial region, and she became short of breath and cyanosed. On several occasions she lost consciousness. Attacks lasted for 15-60 minutes, and she felt weak for a day or two afterwards. They had become more frequent and more severe, and she had been an invalid for a year. She was undersized and nervous. The 
Wassermann reaction was positive. Her uterus was undeveloped, but the other organs seemed sound. The pulse was very unstable, the rate, usually 40-70, varying between 40 and 126 per minute. On one occasion it ran 18-25 for a short period. The electrocardiogram showed a sinus arrhythmia and sino-auricular block. When she was under an anæsthetic, for curetting, the rhythm changed to an auriculo-ventricular nodal rhythm with a pulse rate of 83-97. Subsequently the rhythm became normal but later reverted to the original sinus irregularity.

Barlow (1927) reported several cases of sino-auricular block. A man, aged 65 , who suffered from chronic arthritis, had an attack of giddiness one morning three years before he came under observation, with pain in the shoulder and breathlessness. His blood pressure was 190/90 mm., his heart was enlarged, and a systolic murmur was audible at the aortic cartilage. Sinoauricular block persisted for several months, but he had few discomforts. Another man, aged 41, complained of breathlessness, faintness, and exhaustion of two years' duration. His blood pressure was $140 / 70 \mathrm{~mm}$., his heart of normal size, his mitral valve incompetent. The Wassermann reaction was positive. The electrocardiogram showed sino-auricular block. His condition remained unaltered for the next two years; and three years later he merely complained of lassitude although the block persisted.

In three of these cases syncopal attacks occurred on more than one occasion. The common causes of syncope are vaso-motor disturbances, and failure of the pulse from any cause, producing anæmia of the brain. If the failure is momentary the patient becomes pale ; if it lasts for 4-5 seconds consciousness is lost ; if for 10-12 seconds tonic or clonic convulsions supervene.

Attacks can be produced by pressure upon the carotid arteries. They occur in about one-third of the cases of heart-block most frequently at the period when the rhythm is changing from a partial to a complete block, and ventricular standstills occur from time to time. They are uncommon after full block has been established. I have recorded (1926) their occurrence in a case of paroxysmal nodal tachycardia, where the pulse failed during the paroxysms (Fig. 4).

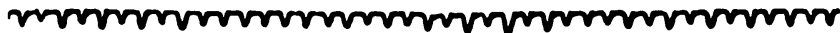

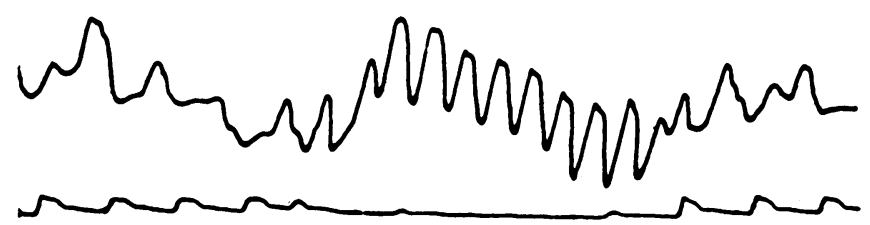

P.R. 160

FIG. 4.-Polygraph tracing showing failure of the radial pulse during a short attack of nodal tachycardia. Case L, p. 19. P.R. 160.

Syncope may occur in sino-auricular block if the standstill is sufficiently 
prolonged. The sequence was clearly proven in Laslett's case. The association of attacks of giddiness, faintness, and syncopes with periods of ventricular standstill in my case and that of Heard and Strauss suggest a similar origin ; but no attack occurred under observation.

Sino-Auricular Block: Type B.-When the sino-auricular stimulus is late in arriving and the auriculo-ventricular node supplies a stimulus for the ventricular contractions.

In this group of cases of sino-auricular block ventricular standstills do not persist for any length of time. On the failure of an auricular stimulus and the consequent prolongation of diastole, the inherent rhythmicity of the auriculo-ventricular node comes into action and evokes a ventricular beat (Fig. 5). As a rule the sinus node regains control of the ventricular contractions

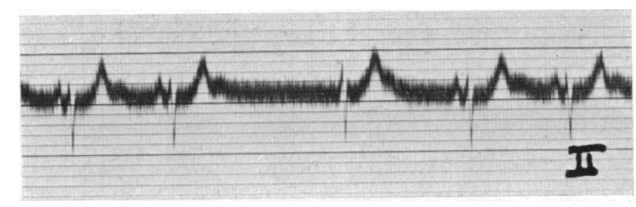

FIG. 5.-Sino-auricular block : type B. Case C. Following the failure of a sinus stimulus and undue prolongation of diastole the auriculo-ventricular node sets the ventricular rhythm for one beat. Lead II.

after but one failure, but occasionally the auriculo-ventricular nodal rhythm continues for several cycles (Fig. 6). In some cases the change of rhythm recurs repeatedly in an irregular fashion.

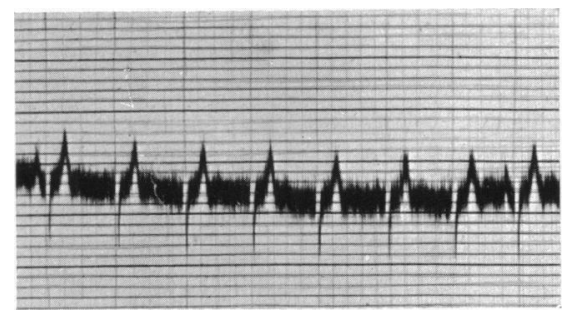

FIG. 6.-Sino-auricular block : type B. Case D. Following the failure of a sinus stimulus and undue prolongation of diastole the auriculo-ventricular node sets the ventricular rhythm for six beats. Lead II.

Case $C$. An active man, aged 57, had been liable to headaches, but otherwise had enjoyed good health until four years prior to his visit, when he became subject to indigestion and various muscular pains. He was thin and nervous, and looked older than his years. His organs seemed sound, but his pulse, numbering about 60 per minute, was very irregular. The electrocardiogram showed a fairly regular sinoauricular rhythm, with at times sino-auricular block : type B (Fig. 5).

His health improved though the irregularity persisted, and he continued at work for five years. At this time, after business worries, he had to enter a mental hospital, where he remained for four months. He was always eccentric in his habits and he had a family history of mental troubles. A year later he was seen again; he looked stout and well, and only complained of slight breathlessness and discomfort in the chest upon exertion. His heart was larger than before and his blood pressure higher, 
$170 / 85 \mathrm{~mm}$. Hg., but there was little evidence of cardiac mischief. His pulse was infrequent, about 38 per minute, and very irregular as the pacemaker "wandered." In some records a fairly regular sinus rhythm continued for several beats, and was suddenly succeeded by a series of ventricular complexes without any evidence of auricular activity. On two occasions an inverted $\mathrm{P}$ was visible between RS and T (Fig. 7). In Fig. 8, taken just after Fig. 7, a positive $P$ immediately preceded QRS

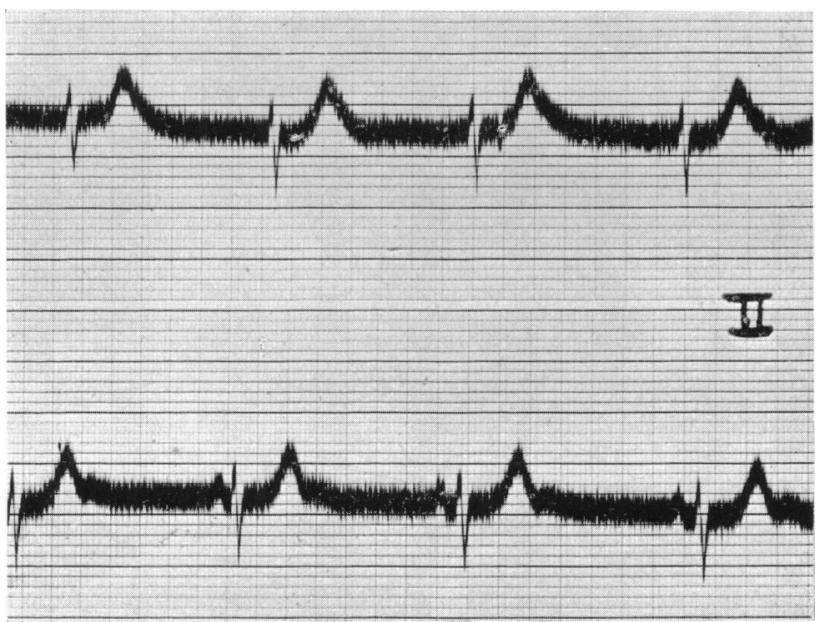

FIG. 7.-Sino-auricular block : type B. Case C. The upper record shows four beats of auriculo-ventricular nodal origin. An inverted $P$ is visible between $R S$ and $T$ in the third complex. The lower record shows a return to sino-auricular control. Lead II.

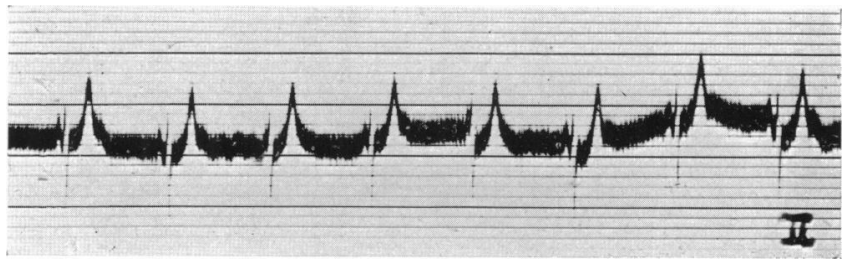

Fig. 8.-Dissociation. Case C. The sinus rhythm is infrequent and irregular. The second auricular diastole is prolonged, and the auriculo-ventricular node, impatient at the delay of the auricular stimulus, sets the ventricular rhythm for the next three beats, after which the sinus rhythm becomes re-established. Lead II.

merging into the upstroke of $R$. The interpretation is difficult on account of the varying rate of the auricular contractions. The inverted $\mathbf{P}$ waves are evidently due to retrograde auricular activation, and their close proximity to QRS seems to preclude the possibility of $\mathbf{P}$ deflexions being buried in the other ventricular complexes. Probably the auricles were at rest save on these occasions : a high-grade sino-auricular block. The sinus rhythm in Fig. 8 is infrequent and irregular. The second auricular diastole is prolonged so the auriculo-ventricular node, impatient at the delay of the auricular stimulus, sets the ventricular rhythm for the next three beats (dissociation), after which the sinus rhythm becomes re-established.

The records are interesting as they show the persistence of comparable cardiac irregularities over a period of at least six years, without any appreciable cardiac difficulties even during his severe mental illness. 
Case D. A man, aged 58, was seen after an attack of influenza. He felt uncomfortable when walking, but he would not admit of any dyspnœa, palpitation, or œdema. He had become liable to attacks of giddiness, and had lost consciousness on several occasions. His heart was normal in size. Systolic murmurs were audible in all areas. His arteries were degenerate and his blood pressure was 155/110 mm. His pulse numbered about 66 per minute and was irregular-a fairly regular sinoauricular rhythm, with at times sino-auricular block, type B (Fig. 6).

After resting for a couple of months his health improved, though the sino-auricular block persisted. He returned to work, but after a year retired from business. Three years later anginous symptoms arose, and a year later he had a slight stroke. His heart was now enlarged, the mitral valve incompetent, and his blood pressure lower, $140 / 90 \mathrm{~mm}$. His pulse was fairly regular and numbered about 66 . The electrocardiogram showed a normal rhythm, but evidence of myocardial damage. He died a year later in an anginous attack.

In this patient sino-auricular block was present at a time when, although his heart was unsound, cardiac symptoms were in abeyance ; and had ceased, at a later date, when cardiac symptoms were clamant.

Case E. A well-to-do plumber came under observation in 1932, at the age of 61 . He had contracted syphilis at 57 . He had had a cough for many years, and was short of breath upon exertion, and liable to attacks of dyspnœa, sometimes without obvious cause. There was a chronic broncho-pneumonia at the left base. With care he regained fair health, leading a quiet life. In 1936, when he was seen after an attack of tonsillitis, merely complaining of shortness of breath upon exertion, the basal consolidation appeared to be larger than before.

In 1932 his heart seemed normal in size. The first sounds were rather weak and distant, and the second sound was doubled. His pulse numbered about 67 and was irregular ; there was a fairly regular sino-auricular rhythm, with at times sino-auricular block, type B (Fig. 9). In 1936 his heart seemed unaltered, but the doubling of the

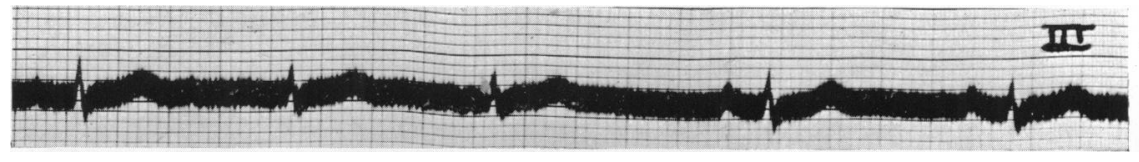

FIG. 9.-Sino-auricular block : type B. Case E : 1932. The first beat is of sinus origin and is followed by two beats in response to auriculo-ventricular nodal stimuli, succeeded by two beats of sinus origin. Lead III.

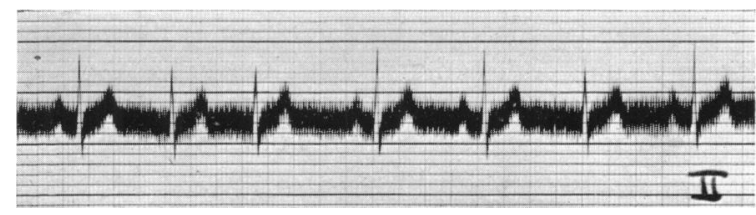

FIG. 10.-Sino-auricular block : type B. Case E : 1936. The second, third, and sixth beats are in response to auriculo-ventricular nodal stimuli. Lead II.

second sound had ceased. The pulse, 60-70 per minute, was again irregular. The electrocardiogram showed an intermittent sino-auricular block as before (Fig. 10). Both sets of records showed sinus irregularity and auriculo-ventricular nodal irregularity, the diastolic periods preceding the nodal beats being of very variable duration.

Case $F$. A man, aged 32, came under observation on account of breathlessness 
and palpitation upon exertion. He had a well-marked mitral stenosis, of rheumatic origin. His pulse, numbering about 90 per minute, was irregular. The electrocardiogram showed slight sinus irregularity, and at times sino-auricular block, type B (Fig. 11). He remained in fair health for the next five years, save for occasional attacks of cardiac failure associated with bronchitis. He then had a hemiplegic seizure, and died shortly afterwards.

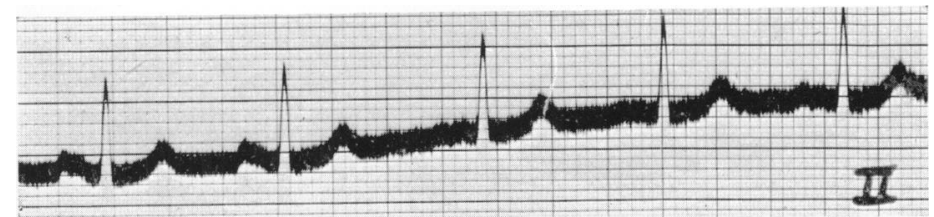

FIG. 11.-Sino-auricular block : type B. Case F. The last three beats are in response to auriculo-ventricular nodel stimuli. Lead II.

The following record is interesting as the changes in rhythm were associated with a cardiac infarct, the only instance in my experience.

Case G. A man, aged 63, had led a wandering life in his early days, been careless in his habits, and contracted many infections. For a year he had been liable to palpitation and giddiness upon exertion. A fortnight before his visit he had had a severe attack, and had been in bed for a few days.

He was a well-built man but obese. He did not look seriously ill, and a minimal amount of œdema on the shins was the only sign of cardiac insufficiency. His heart was large, and double murmurs were audible over the sternum. His blood pressure was $200 / 65 \mathrm{~mm}$., and his arteries showed gross degenerative changes. It seemed clear that he had had an infarct. With care his health improved, and a year later he had few discomforts if he lived quietly. He had had several syncopal attacks, of short duration. His heart was larger than before, his blood pressure $245 / 70 \mathrm{~mm}$., and the albuminuria considerable. He refused to rest ; and a few months later, when in church, he had another infarct, and died two days later.

Electrocardiograms were taken on three occasions. The first (1928) showed an irregular sinus bradycardia (Fig. 12), with a pulse rate of about 30 per minute. In the upper record the rhythm is apparently normal, while the lower shows dissociation with interference, the aberrant complex of the captured beat denoting impaired conduction in the bundle branch on account of the prematurity of the contraction. The second record, a year later, shows a variable sino-auricular block, the auricular rhythm being very irregular and infrequent, and the long pauses allowing the lower centre to capture, or supplement, the ventricular rhythm (Fig. 13). The last record, a fortnight later, showed an almost regular sinus rhythm, with a pulse rate of about 40. The P-R interval measured $0 \cdot 18-0 \cdot 20$ in. (Fig. 13). The irregular sinus bradycardia may have been due to impairment of the blood supply to the sino-auricular node. Barker and Kinsella (1924) reported a case of sino-auricular block in a dog that had an acute streptococcic infection; the almost normal sino-auricular node was completely surrounded by an inflammatory mass.

Cutts (1937) has recorded several cases in which the pacemaker " wandered " from the sino-auricular to the auriculo-ventricular node and back again, in an irregular fashion. The cause of the change of rhythm was evidently varied. One patient, aged 37, complained of general weakness and a tremor of the head for six years. Her pulse was known to have been infrequent for many years. At the time of observation it numbered about 48 per minute, and was irregular. 


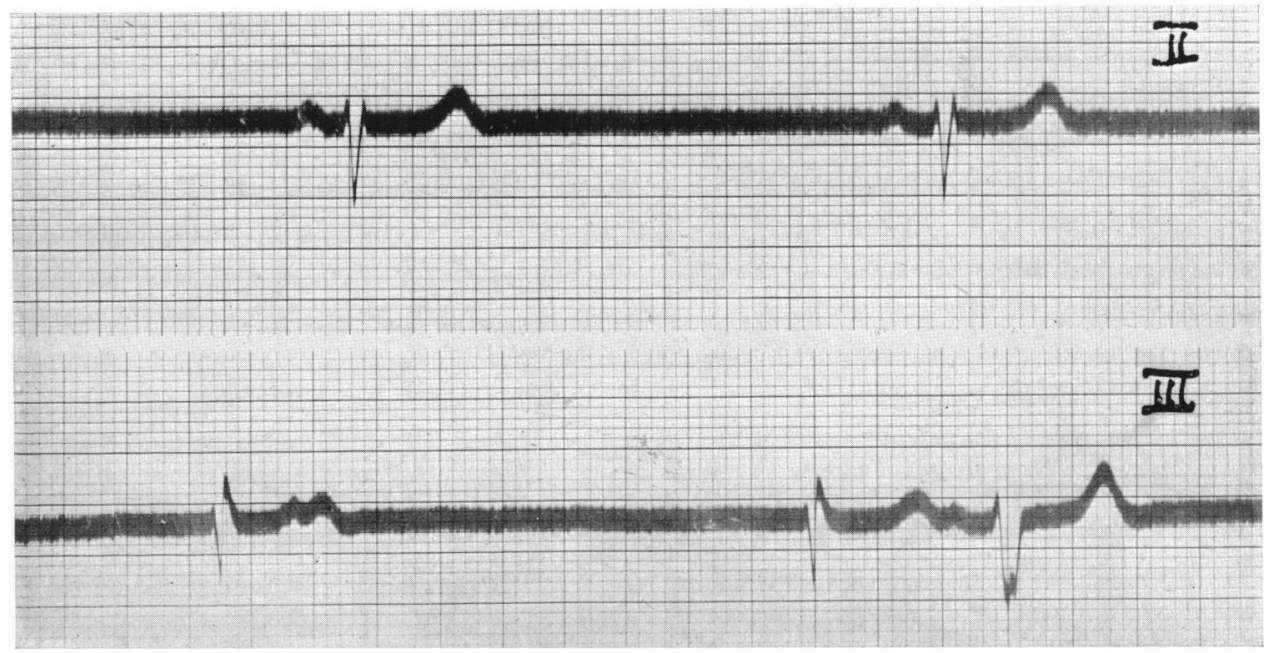

FIG. 12.-Dissociation with interference. Case G. The upper record shows an apparently normal sinus rhythm, with an abnormally slow rate, about 30 per minute. The lower record shows dissociation with capture of the third ventricular systole by the preceding auricular stimulus. The abnormal ventricular complex indicates impaired conduction in the bundle branch. Leads II and III.

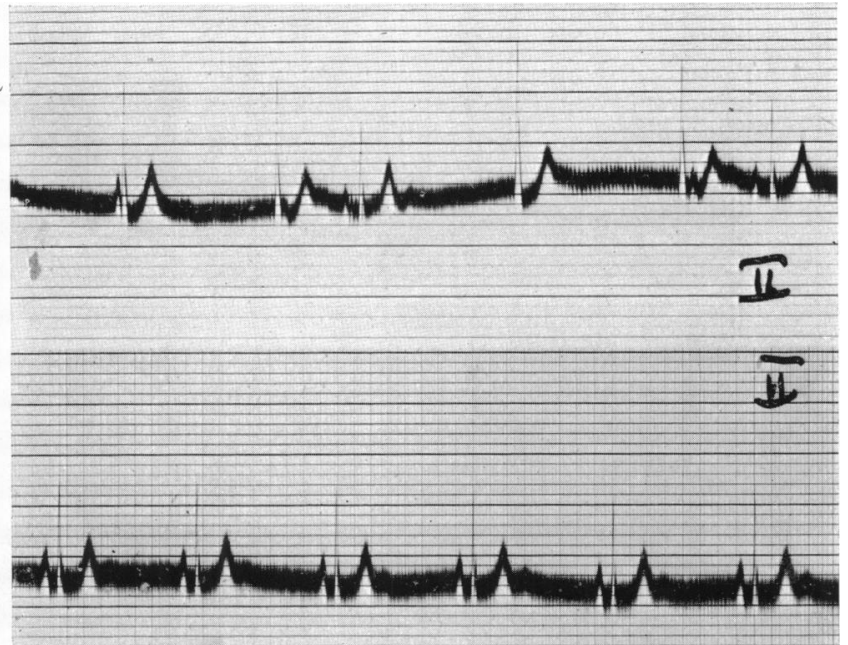

FIG. 13.-Sino-auricular block: type B. Case G. The upper record shows that the auriculo-ventricular node sets the ventricular rhythm whenever diastole is unduly prolonged. The lower record shows a return to normal sinus rhythm. Lead II. 
Her heart seemed to be sound. She made a satisfactory recovery and was well six months later. There was a well-marked sinus irregularity, and when diastole was prolonged the auriculo-ventricular node took charge, and, as in some beats an inverted $\mathbf{P}$ was present between $\mathrm{R}$ and $\mathrm{T}$, evidently originated these auricular contractions.

Another patient, aged 27, was suffering from rheumatic fever, and was fevered at the time of observation; she had aortic and mitral valvular disease. The pulse numbered about 80 , and was irregular. There was little difference in the rate set by the two nodes, and at times the auriculo-ventricular node took charge of the ventricular contractions. As the Ps were positive, when present, there was evidently a retrograde block. The data suggest an enhanced irritability of the auriculo-ventricular node as the cause of the altered rhythm. The patient's health improved, and she was sent home for further rest.

Some other reported cases appear to be examples of sino-auricular block, although the proof is not complete. Lewis (1925) refers to an athlete whose regular pulse of 36 when at rest abruptly rose to double that rate upon moderate exertion, and to a case reported by Neuburger and Edinger, where syncope frequently followed defæcation; an aneurysm of the basilar artery, exerting pressure upon the medullary centres when the blood pressure rose during the act, seemed the probable cause of the attacks: and to Gerhardt's case, where similar attacks were associated with a tumour involving the left vagus nerve. Osler (1909) described a patient who suffered from attacks of syncope with an infrequent pulse of 10-12 per minute, associated with tubercular disease of the first and second cervical vertebræ. The case of de Zarday (1936) is definite ; in a woman, aged 42, suffering from a tumour in the posterior fossa of the skull, the pulse showed intermissions after each sixth systole, due to sino-auricular block. The intraspinal pressure was high, and a normal rhythm ensued for several hours after lumbar puncture. She died during an attempt at encephalography, but a post-mortem examination was not secured.

\section{CONCLUSIONS}

Sino-auricular block is not necessarily accompanied by cardiac symptoms. Four cases came under observation on account of symptoms other than cardiac ; nine cases on account of cardiac symptoms. The heart may be apparently sound (six cases) ; or may show signs of organic heart disease (seven cases).

Sino-auricular block can only be recognized by polygraphic or electrocardiographic examination. It may be suspected as the cause of recurrent syncopes in patients who show, between attacks, gross sinus irregularity.

The presence of sino-auricular block does not affect the cardiac prognosis or treatment in the individual case; which must be based upon the general rather than the cardiac picture.

\section{DISSOCIATION}

Fig. 14 shows an example of dissociation with interference, from the old man (case A) reported on p. 7. His pulse then was fairly regular save for 
occasional extrasystoles, the auricular rate 32.7 per minute, and the ventricular rate 32.8. At first the $\mathrm{P}$ precede waves $\mathrm{QRS}$ with a narrowing interval. Later

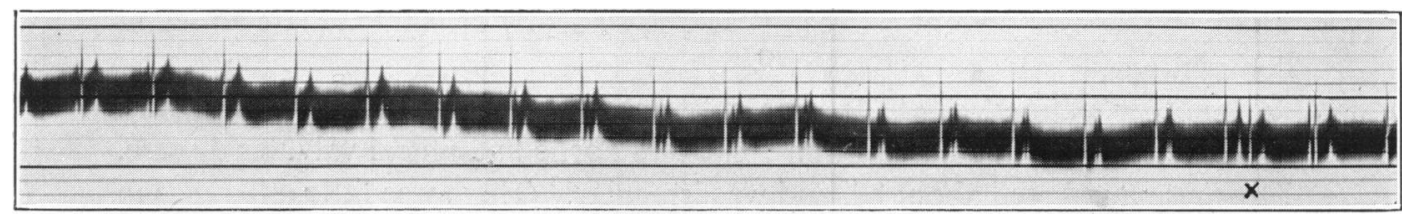

FIG. 14.-Dissociation with interference. Case A. See text. The ventricular beat 18 (x) is due to capture by the preceding auricular stimulus. Lead I.

they become lost in $\mathrm{R}$ and then emerge between $\mathrm{R}$ and $\mathrm{T}$. Finally $\mathrm{P}$ fuses with $\mathrm{T}$ and again becomes invisible. As this auricular stimulus reached the ventricle at a time when it was excitable, it was followed by a ventricular contraction (x) : (capture). With care his pulse rate rose to normal figures, and 3 months later numbered 66 and was almost regular, $P$ preceding QRS by about $0.20 \mathrm{in.}$ On this occasion sino-auricular block was recorded (Fig. 2) ; it continued until his death a month later.

Case $H$. This patient has been under observation, at intervals, for many years. He was born in 1865. A well-built, muscular man, he engaged in athletic pursuits in early life, but permitted himself to become stout and flabby at an early age. He has had many adventures ; infections of varied character ; and has consistently " done himself well." In 1895 G. A. Gibson sent him to bed for cardiac symptoms, accompanied by œdema, which had followed athletic feats on the hill. In 1912 he became subject to attacks of giddiness, probably related to chronic otitic media, and had become unable to sustain continued exertion. "A lion before lunch; a mouse after it." He made similar complaints in 1916 and 1921, and became very nervous. In 1925 he had two syncopes, following long drinks after shooting all day. He was now short of breath upon exertion. In 1930 he had to cease shooting as he tired easily. In 1936 he was leading a quiet life, and was very well.

His heart has always been normal in size, and his blood pressure has never been high ; his arteries are soft. In 1926 QRS was splintered and T3 inverted, but the Ts were positive after 1928. His pulse has been slow-51-57-64-and often irregular from extrasystoles ; in 1926 it showed functional dissociation without interference (Fig. 15). A similar irregularity was noted in 1930, but the rhythm was normal in $1912,1916,1921$, and 1928.

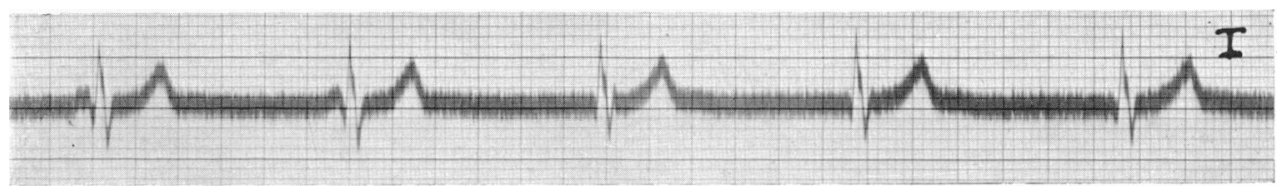

FIG. 15.-Dissociation. Case H. The P-R intervals of the first two beats are shortening, and the succeeding Ps are lost in QRS. Lead I.

Case I. This patient came under observation at the age of 53, on account of pain in an elbow following trauma. He suffered from chronic bronchitis and was liable to asthma. His heart seemed normal to physical examination, but the pulse was slightly irregular and an electrocardiogram showed well marked R-T deviation in leads II and III, and also slight sinus arrhythmia and auriculo-ventricular dissocia- 
tion (Fig. 16). Three days later the sinus irregularity still persisted, but the rhythm was normal and the R-T deviation was less marked. Nine years later he is in fair health and at work. He has never shown any symptoms suggestive of cardiac insufficiency.

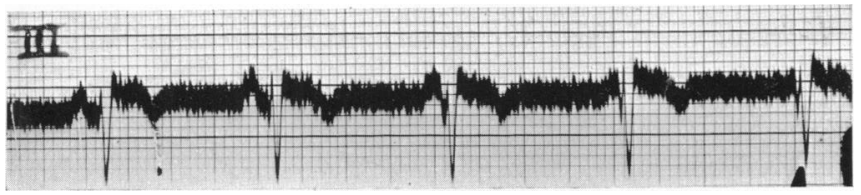

Fig. 16.-Dissociation. Case I. The P-R intervals of the first three beats are steadily shortening. The fourth $P$ merges into $R$, and the fifth is lost in the ventricular complex. Lead III.

Another example of auriculo-ventricular dissociation was shown in Fig. 12, obtained from case G. White (1916) reported the case of a woman, aged 24, whose heart appeared to be sound. When convalescing after removal of the tonsils four days previously, her pulse was noticed to be slightly irregular and she complained of palpitation. The electrocardiogram showed dissociation, the auricles beating 67-85 times per minute and the ventricles 96. Next day the rhythm was normal, but dissociation was readily produced by pressure upon either carotid sinus, which slowed the auricular rate from 80 to 68 , and thus permitted the escape of the auriculo-ventricular node. She was up and about at the time of the observation.

Hewlett (1923) reported the case of a man, aged 75, seen for shortness of breath, œdema of the feet, and pain in the chest upon exertion. His heart was enlarged, with a diastolic murmur sometimes audible at the apex, and a raised blood pressure, $175 / 110 \mathrm{~mm}$. At intervals over a period of months dissociation was present ; generally the ventricular contractions $(84,88,84,75)$ were more frequent than the auricular $(73,71,71,72)$, but on one occasion the auricular rate was 75 and the ventricular rate 66 . The pulse rate varied between 66 and 96. Atropine increased the ventricular rate and pressure over the carotid sinus slowed it. Large doses of digitalis slowed the auricular rate, but did not affect that of the ventricles.

Enescu and Vacareanu (1934) reported two cases of dissociation. One was suffering from rheumatic fever ; some sinus arrhythmia was present, with a pulse rate of 56. On the fourth day dissociation was recorded, there being but little difference between the auricular and the ventricular rates. The rhythm had returned to normal three days later. The second man, aged 32, complained of attacks of vertigo, and his pulse numbered about 68 . There was usually sinus arrhythmia, and a P-R interval of $0 \cdot 22$ in. On one occasion dissociation was present, with a pulse rate of 61 . The general picture suggested myocardial mischief. Neither of these patients had taken any digitalis.

Ritchie (1935) reported two cases of dissociation. One, a woman aged 44, was admitted into hospital on account of congestive failure, due to a diffuse myocardial fibrosis. After some improvement, the pulse rate falling from 90 to $60-63$, she soon relapsed and digitalis was exhibited. The rhythm was 
normal, but five days later interference dissociation was present, the auricular rate being 60.7 and the ventricular rate 73.1 per minute. She died two days later. His second case, also a woman aged 44, was suffering from congestive failure, with mitral stenosis. She had been taking digitalis for some months prior to admission. Dissociation was present, the auricular rates being 42 , 45,57 and the ventricular rates $75,74,87$. It continued until her death eleven days later.

\section{CONCLUSIONS}

The conditions which were associated with the occurrence of dissociation in these ten cases were varied. In one it accompanied an infarct; and in seven cases there was evidence of myocardial mischief. In two the heart was apparently sound. Dissociation is often associated with the administration of digitalis, and accompanied it in several of the cases mentioned above ; but in four cases no digitalis had been given.

There are no special symptoms associated with dissociation. In four of these patients symptoms of cardiac insufficiency were present, and two complained of cerebral symptoms. One was suffering from rheumatic fever, two merely complained of irregularity of the heart, and one made no complaint referable to the heart.

Dissociation can only be recognized by electrocardiograms. Its occurrence does not affect the outlook from the cardiac standpoint. It does not call for any specific treatment, but its frequent association with the administration of digitalis suggests that the dose, if not altogether discontinued, should be of moderate amount.

\section{THE NODAL RHYTHMS}

The various forms of auriculo-ventricular nodal rhythm may be conveniently divided into three clinical groups :

(1) those with paroxysms of trachycardia ;

(2) those with a persistent frequent pulse rate ;

(3) those with the pulse rate unaltered, or less frequent than normal.

(1) Paroxysmal Nodal Tachycardia.-This group is the most common form of paroxysmal tachycardia (146 of 325 cases). It occurs at all ages, and need not occasion any distress save palpitation, unless, from long continuance of the tachycardia or pre-existing cardiac disease, the muscle of the heart becomes exhausted. The clinical story is varied.

Case J. A healthy boy of 16 had had attacks of palpitation at irregular intervals as long as he could remember. They lasted for variable periods, sometimes for several days. During the attacks the pulse ran about 220-240 per minute. Between attacks he was fit and well. His organs seemed sound.

Case $K$. An active country gentleman found, at the age of 69 , that he was becoming subject to attacks of palpitation and shortness of breath upon exertion, steadily increasing in frequency and severity. During the attacks the pulse numbered about 136 per minute. His blood pressure, heart, and blood vessels seemed in reason- 
able condition for his age. The electrocardiogram showed that $\mathbf{P}$ was hidden in R. After a few months hepatic colic ensued, and a gall-stone was removed successfully. The attacks then lessened in severity, and he became able to resume his former field activities. Ten years later he is leading a quiet life and in reasonable health. The attacks are now infrequent and of short duration.

If, however, the heart is already weak the outlook is serious.

Case $L$. A done old man, aged 77, was admitted into hospital complaining of attacks of giddiness, and of faints in some of which he had fallen to the ground. He was emaciated, childish, and restless, and steadily deteriorated both mentally and physically during his residence.

Many attacks were witnessed. The striking feature was failure of the pulse. If the failure was of short duration, a few seconds, he became restless and sometimes ceased to breathe ; if for 10 seconds he became very pale and lost consciousness. On several occasions when the pulse failed for a longer period the muscles twitched, and less often generalized convulsions ensued.

His heart was normal in size and site. The sounds were closed but short and distant. All his arteries were tortuous and thickened. His blood pressure varied : $115-155 / 60-95 \mathrm{~mm}$. The cardiac rhythm was very unstable. His pulse might be regular even for days, but was often irregular from extrasystoles, which might be isolated events in a long series of regular beats, or, more often, bigeminal, trigeminal, or wholly irregular in incidence. When the radial pulse failed the cervical veins at once became greatly distended, pulsating vigorously at about double their usual rate (160 per minute). Polygraph tracings showed large venous waves and lessened arterial volume (Fig. 4). The electrocardiogram showed an inverted $\mathbf{P}$ between $\mathbf{R}$ and $\mathrm{T}$. It was clear that the tachycardia rapidly exhausted an already weakened myocardium.

In several of our patients, with a degenerate heart, attacks of paroxysmal tachycardia were associated with serious symptoms if the attack lasted for long, or as age increased.

Case M. A man who was recognized to have paroxysmal nodal tachycardia at the age of 60 , had probably had his first attack at the age of 27 , following typhoid fever. The attacks ceased for some years, but recurred at the age of 50, and continued. He had a high blood pressure and degenerate arteries. In his early life the paroxysms occasioned little discomfort, but as he grew older caused great exhaustion. He aged quickly, the attacks recurred every month, and when 63 an attack occurred and persisted, the pulse running 180-200 per minute until death ensued after 72 hours.

(2) Continued Nodal Tachycardia.-In a small number of cases nodal tachycardia has been observed in patients suffering from an infective disease, most commonly acute rheumatism and "bacterial" endocarditis. The onset of the rhythm may be preceded by nodal extrasystoles.

Case N. A man, aged 27, was admitted into hospital in 1922, suffering from acute rheumatism. Both the mitral and the aortic valves were affected, but he made a good recovery and resumed his work. In 1925 symptoms of cardiac failure ensued, followed by arthritis, and his progress was unsatisfactory ; the congestive symptoms increased, many veins became thrombosed, and infarcts occurred in the lungs and spleen. He died in February 1926, evidently with a "bacterial" endocarditis. During his last illness his fever was never high, not exceeding $101^{\circ} \mathrm{F}$. His pulse at first was regular, numbering about 100 per minute. But five days before his death it rose to 150-160, and continued so until the end. The electrocardiogram showed a nodal rhythm, an inverted $P$ appearing between $S$ and $T$ (Fig. 17). 
Case $O$. A man, aged 42, was admitted into hospital on the fifth day of an acute pneumonia. His pulse was frequent and regular save when interrupted by an extrasystole. Next day there was a regular nodal rhythm, with a hidden $\mathbf{P}$ at the rate of 144 (Fig. 18). Next day his auricles were fluttering, and continued to flutter until

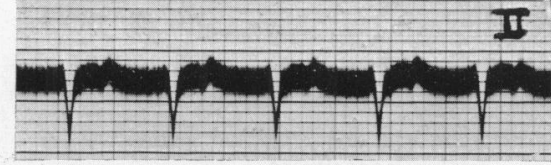

Fig. 17.-Nodal rhythm. Group 2. Case N. An inverted $\mathbf{P}$ is visible between $\mathbf{S}$ and $\mathrm{T}$. Lead II.

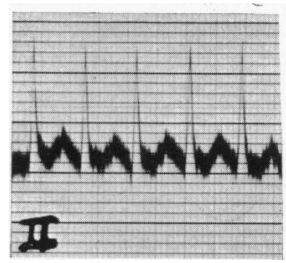

Fig. 18.-Nodal rhythm. Group 2. Case O. $P$ is lost in the ventricular complexes. Lead II.

his death on the ninth day of illness. The mitral and aortic valves showed chronic endocarditis, with superadded acute re-infections. The myocardium showed an extensive patchy fibrosis. The nodes, unfortunately, were lost.

Cowan et alii (1913) reported six cases of acute endocarditis whose polygraph tracings showed a short a.c. interval. Microscopic examination disclosed involvement of the a.v. nodes in acute inflammatory lesions. The cardiac rhythm in these patients was regular, save for occasional extrasystoles, the maximum rate in the several cases being $105,120,140,140,140,145$ per minute.

Hume (1914) reported the occurrence of nodal rhythm during a small epidemic of diphtheria. A girl, aged 7, showed auricular extrasystoles on the ninth day of illness ; nodal rhythm with a pulse rate of 109 on the tenth and eleventh days; auricular flutter on the twelfth day; and a regular rhythm save for some auricular extrasystoles on the thirteenth day. She died on the fifteenth day of illness. A gross interstitial myocarditis was found, the a.v. node and bundle being unaffected. A boy, aged 7, had a normal rhythm on the seventh and eighth days of illness ; extrasystoles on the ninth day; nodal rhythm with a pulse rate of 94 on the tenth day ; and 2-1 heart-block on the twelfth and thirteenth days. He died next day. The s.a. node was acutely inflamed and the a.v. bundle was engorged. The a.v. node, unfortunately, was lost.

(3) Nodal Rhythm without Tachycardia.-In this group the pulse rate is little altered, or less frequent than normal.

Case $P$. A gamekeeper, aged 55, was seen in 1914 for a strain of his right shoulder which had kept him off work for some weeks. He was a sparely built fellow, who looked younger than his years. He would not admit of any disability, and said that he could carry 14 couples of rabbits for a mile and a half without discomfort. His brachial arteries were thick and tortuous, but his heart seemed sound. His pulse numbered 75. The electrocardiogram showed normal ventricular complexes, and an inverted $\mathrm{P}$, less than $0 \cdot 10$ sec. in front of $\mathrm{R}$ (Fig. 19). A fortnight later the rhythm was unaltered. He continued at work, but refrained from carrying heavy weights. A year later he was in good health. On this occasion the cardiac pacemaker was mobile, wandering between the sino-auricular and the auriculo-ventricular nodes, 
though the pulse rate (69) did not alter. A normal rhythm, with P-R 0.14 in., changed within a couple of beats to a nodal rhythm with an inverted $P$, less than 0.10 in. before $\mathrm{R}$ (Fig. 20). The normal rhythm returned shortly afterwards, but the

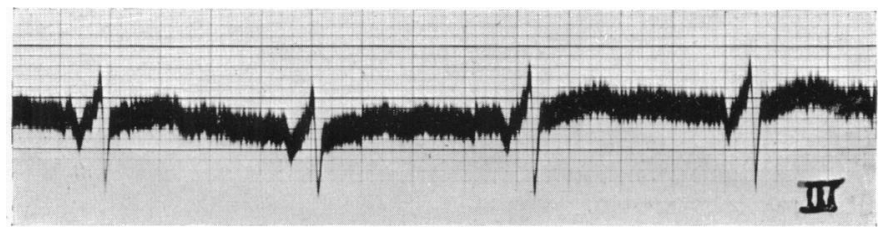

FIG. 19.- Nodal rhythm. Group 3. Case P. P is inverted and precedes RS by $0.08-0 \cdot 10 \mathrm{sec}$. Lead III.

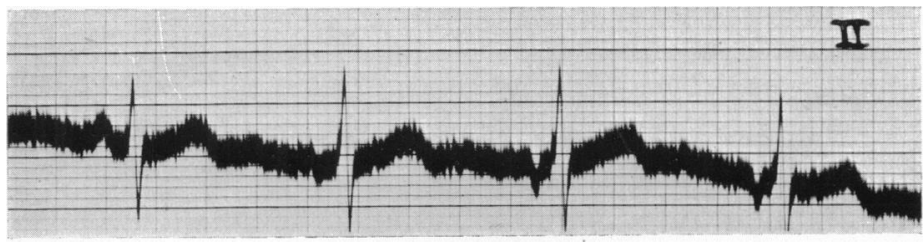

FIG. 20.-Nodal rhythm. Group 3. Case P. This record shows the transition from the sino-auricular to the auriculo-ventricular rhythm. Lead II.

change was not observed. In 1919, 1920, 1921 he was in good health, with a normal rhythm. In 1936, at the age of 76 , he is still active as a grieve, and looks well and young for his age. His organs seem healthy and the cardiac rhythm is of sinus origin. An occasional extrasystole was missed in the electrocardiogram.

Boukspan (1928) reported the case of a locksmith, aged 29, who showed a nodal rhythm, with a pulse rate of $36-40$, over a period of seven months. $\mathrm{He}$ had suffered from syphilis five years before, but the Wassermann test was negative. The first sound at the apex was " rough." On exertion his pulse rate rose to $44-46$, and after atropine to 75 . During the period of infrequent rate $P$ was hidden, but when under the influence of atropine it reappeared, as a positive deflexion, before or after R. He continued at his work.

Wedd and Wilson (1930) reported the case of a man, aged 22, who had an apparently constant nodal rhythm. He had had a hemiplegic stroke at the age of 16, and was weak-minded. The mitral valve was stenosed. The usual pulse rate was about 60 , but at times it fell as low as 36 , and it sometimes failed for several seconds. This might.occur spontaneously, or be induced by scolding or a sudden order. The pace-maker was not affected by atropine, or pressure upon the carotid sinus or the eyeballs, but the rate, when infrequent, was accelerated by exercise and atropine ; so the standstills were evidently vagal in origin.

Ledoux (1935) reported the case of a young farmer, aged 26, whose electrocardiograms invariably showed nodal rhythm, $\mathrm{P}$ appearing between $\mathrm{R}$ and $\mathrm{T}$, over a period of eighteen months. His pulse rate was habitually infrequent, 
30-60 per minute, and very variable. Syncopal attacks had recurred frequently when his pulse rate was low, but none was observed during his residence in hospital.

The following cases of nodal rhythm were under observation, at the time when the disordered rhythm was observed, on account of some form of cardiac disability.

Ritchie (1914) reported the case of a man, aged 72, with congestive cardiac failure, and high blood pressure. His pulse at first was grossly irregular with numerous nodal extrasystoles. On several occasions nodal rhythm supervened for an indefinite period, the pulse running in the nineties. Under treatment he improved, and the rhythm became normal. Another man, aged 47, was suffering from subacute myocarditis, without valvular lesions. For about a month a normal rhythm, with a pulse rate of about 90 , alternated with a nodal rhythm, with a pulse rate of about 80 . He improved for a time and resumed his work, but the improvement was transitory. His auricles went into fibrillation, and cardiac failure ensued. He died three and a half months after coming under observation. The cardiac muscle showed widespread fibrosis and cellular infiltration. The a.v. node and bundle were grossly involved.

White (1915) reported the case of a man, aged 37, who complained of obesity and weakness of the legs, probably due to early tabes dorsalis. His heart was normal in size and the sounds were closed and of fair value. His pulse on admission was 120 , and there was a uricular flutter with defective conduction in the bundle branch (Type I). Ten days later the auricles were fibrillating. Four days later the rhythm was nodal, and this persisted for the next four months, the pulse rate falling to $40-43$.

Matthewson (1915) reported the case of a man, aged 22, whose pacemaker frequently changed from the sino-auricular to the auriculo-ventricular node. $\mathrm{He}$ complained of shortness of breath and palpitation. His mitral valve was incompetent. His pulse numbered about 70 and the change of pacemaker recurred without any obvious change in the rate of the pulse, either node becoming dominant in an inconsistent fashion. When the rhythm was nodal compression of the carotid sinus failed to influence the pacemaker, but atropine and gentle exertion caused a return to normal rhythm.

A woman, aged 62, reported by Fussell and Wolferth (1920), had complained of attacks of palpitation since childhood, at first of little moment, but gradually increasing in frequency and in severity, till she had been forced to lead an invalid life for a couple of years. She had become short of breath upon exertion, and had noticed some edema of the feet. After leaving hospital she died from cardiac failure. Her heart was slightly enlarged, and the mitral valve was incompetent. The attacks of palpitation occurred at any time, on exertion or during sleep. They could always be checked by holding her breath. They were due to an auricular tachycardia, and the pulse rate rose to 135 per minute. Her pulse rate was very variable, as the pacemaker shifted irregularly between the sino-auricular and the auriculo-ventricular nodes, the nodal rhythm persisting for a few seconds or as long as several minutes. The nodal rhythm might develop gradually, with decreasing $P-R$ intervals, the rate gradually 
slowing to $30-45$ per minute ; or suddenly without any appreciable change in rate.

Richardson (1922) reported the case of a woman, aged 47, who was suffering from mitral disease and chronic nephritis. A normal rhythm, with a blood pressure of $150 / 98 \mathrm{~mm}$., changed under the influence of digitalis to a nodal rhythm, with a pulse rate of $38-43$ and a blood pressure of $180 / 120 \mathrm{~mm}$. Atropine and pressure over the carotid sinus had no effect upon the pacemaker. She died eventually from pneumonia. The mitral and tricuspid valves were thickened, and the aortic valve acutely inflamed. Scars were present in the right auricle, and the ventricles showed a general fibrosis. The s.a. and the a.v. nodes were normal.

\section{CONCLUSIONS}

\section{Causation of the Nodal Rhythms}

1. Paroxysmal Nodal Tachycardia.-The nature of the paroxysmal change in rate is not clear. The sudden onset and termination of the paroxysms suggest a nervous cause, cessation of the controlling activity of the vagus, or overaction of the accelerator mechanism. But the failure of vagal stimulation to control the tachycardia, save in very exceptional cases, shows that the nervous control is temporarily lost, from some obscure cause.

2. Continued Nodal Tachycardia.-Continued nodal tachycardia has hitherto been observed only in cases of acute myocarditis, and the change in rhythm is presumably due to involvement of the auriculo-ventricular node in an inflammatory mass.

3. Nodal Rhythm without Tachycardia.-This group in which the pulse rate is unaltered or slowed evidently owns several causes. In some patients the heart is apparently sound, in others grossly diseased. In some the change of rhythm ensues during the exhibition of digitalis and ceases on withdrawal of the drug. In some the normal rhythm follows the administration of atropine, but in others the abnormal rhythm is unaffected. It thus seems clear that some cases are due to vagal overaction, whether spontaneous or induced by digitalis, and the consequent domination of the rhythm by the auriculoventricular node. But the cases which are not influenced by atropine must own a different cause, perhaps of myocardial origin.

\section{Diagnosis of Nodal Rhythm}

This can only be established by polygraphic or electrocardiographic records. Its occurrence can sometimes be suspected by the appearance of large pulsatile waves in the jugular veins, caused by the coincident contraction of the auricles and ventricles, closing the tricuspid valve and so entailing the reflux of the auricular blood into the veins when the right auricle contracts. 


\section{Prognosis of the Nodal Rhythms}

1. Paroxysmal nodal tachycardia is not incompatible with long life. In patients whose hearts are sound, and cardiac reserve between paroxysms ample, the immediate and the ultimate outlook is good. If an attack persists for many hours symptoms of cardiac insufficiency may arise, but they rapidly subside on cessation of the tachycardia.

The outlook is, however, serious in patients whose hearts are unsound, as the tachycardia rapidly exhausts an already weakened heart; and is more serious if symptoms of cardiac weakness already exist.

2. Continued nodal tachycardia always makes the outlook serious, as it seems to be indicative of acute myocarditis. Its occurrence in the cases hitherto reported has always been followed shortly by death.

3. Nodal rhythm without tachycardia with an unaltered or a slowed pulse rate has a variable outlook according to the cause. It is serious in the cases where the alteration in rhythm is due to a myocardial lesion and in those due to digitalis, as the exhibition of the drug predicates some pre-existing cardiac difficulty. In the nervous cases the outlook is good.

\section{SUMMARY}

Alterations in the rhythm of the heart, as isolated signs, are not necessarily of serious significance.

James Mackenzie stated (1912) that sinus irregularity, in a healthy individual, was a normal occurrence, and many observers have subsequently confirmed the accuracy of his dictum. It is true that sino-auricular block may, as shown in some of the cases which we have collected, be accompanied by serious symptoms, but the subsequent history of these patients shows that, in the absence of signs of cardiac disease, the prognosis from the cardiac standpoint is quite good. Any danger lies in the nature of the nervous disorder which occasions it.

The occurrence of extrasystoles, per se, has not any sinister significance. It is true that if they recur rapidly for long periods the mere rapidity of the cardiac contractions may produce cardiac failure, but, in the absence of signs of cardiac disease, any cardiac symptoms rapidly pass as soon as the normal rhythm is restored. A man, who died from paralysis agitans at the age of 75 , had been liable to attacks of paroxysmal tachycardia from the age of 18 , and had lived a very strenuous life for many years.

The prognosis in cases of nodal rhythm depends, as in sinus irregularity, upon the nature of its cause. The outlook is serious if it is due to myocardial lesions ; but good if it is due to nervous causes.

The occurrence of auricular fibrillation is generally a signal of impending danger, but the exceptions to the rule are fairly numerous. Cases have been reported where the arrhythmia persisted for ten or even twenty years. One of my patients bore a child safely although her auricles had been in fibrillation for at least three years. The irregularity is not the important factor in the 
failure. The danger lies in the frequency of the ventricular contractions or in the continued activity of the cause of the irregularity. Fibrillation may be due to several causes : pathological lesions in the auricular muscle, of chronic or acute character ; auto-intoxications, as in Graves' disease ; poisons introduced from without (digitalis, anæsthetics, coal-gas poisoning, etc.) ; physical stresses ; and perhaps to disturbances of the nervous control of the heart (Cowan 1929). The cause may be permanently or temporarily in action. The prognosis follows the cause.

Heart-block and bundle branch block repeat the story. As they are most frequently due to myocardial disease the prognosis is, as a rule, serious, but many patients live in fair health for many years. Again the danger lies in the rate of the ventricular contractions, or in the character of the process which has disturbed the rhythm of the heart.

This paper is based upon electrocardiographic records, upon what may be called laboratory methods of diagnosis. But it seems to me that there is a tendency at the present time to overestimate the value to clinical medicine of such methods. The wood tends to be hidden by the trees, and an attempt is made to treat a symptom, or even a sign, and not a sick man.

An irregular pulse is a useful signpost, but the causes of irregularity are numerous, and not necessarily disease of the heart. In many cases treatment, if it is to be helpful, must be based upon the general picture of the illness, and directed to regions outwith the heart.

I have great pleasure in acknowledging the kindly assistance of many friends ; in particular G. B. Fleming, A. G. Gibson, I. G. W. Hill, and E. E. Laslett.

\section{REFERENCES}

Barker, P. S., and Kinsella, R. A. (1924). Heart, 11, 81.

Barlow, P. (1927). Lancet, 1, 65.

Boukspan, M. (1928). Arch. Mal. Coeur, 21, 802.

Broadbent, W. H. (1890). The Pulse, London.

Cowan, J. (1926). Edin. med. J., 33, 465.

(1929). Quart. J. Med., 22, 237.

Cowan, J., Fleming, G. B., and Kennedy, A. M. (1913). Trans., 17 ${ }^{\text {th }}$ Internat. Congress, London, Sect. 6, 223.

Cushny, A. R. (1925). Digitalis, London, 1925.

Cutts, F. B. (1937). Amer. Heart J., 13, 451.

de Zarday, I. (1936). Amer. Heart J., 12, 339.

Enescu, I., and Vacareanu, N. (1934). Arch. Mal. Coeur, 27, 690.

Fleming, G. B., and Stevenson, M. H., (1928). Arch. of Dis. Child., 3, 221.

Fussell, M. H., and Wolferth, C. C., (1920). Arch. intern. Med., 26, 192.

Gibson, G. A. (1898). Diseases of the Heart, Edinb.

, (1904). Morison Lectures, Edinb.

Heard, J. D., and Strauss, A. E. (1918). Amer. J. med. Sci., 155, 238.

Hewlett, A. W. (1923). Heart, 10, 9.

Hume, W. E. (1913-14). Heart, 5, 25.

Laslett, E. E., (1908-09). Quart. J. Med., 2, 347. 
Ledoux, E. (1935). Arch. Mal. Coeur, 28, 541.

Lewis, T. (1925). The Mechanism of the Heart Beat, London.

Mackenzie, J. (1902). The Study of the Pulse, London.

- (1912). Brit. med. J., 2, 1697.

Matthewson, G. D. (1915). Quart. J. Med., 9, 1.

Osler, W. (1909). Allbutt's System of Medicine, 6, 145.

Richardson, H. B. (1922). Arch. intern. Med., 29, 253.

Ritchie, W. T. (1914). Auricular Flutter, Edinb. (1935). Diseases of the Heart, London.

Stokes, W. (1854). Diseases of the Heart, Dublin.

Wedd, A. M., and Wilson, D. C. (1930). Amer. Heart J., 5, 493.

White, P. D. (1916). Arch. intern. Med., 18, 243.

- (1915). Arch. intern. Med., 16, 517. 